Note

\title{
Antibiotic literacy among Japanese medical students ${ }^{\text {t3 }}$
}

\author{
Hideharu Hagiya ${ }^{\text {a, }}{ }^{\text {, }}$, Hideo Ino ${ }^{\text {b }}$, Kazuki Tokumasu a , Hiroko Ogawa a, c, \\ Tomoko Miyoshi ${ }^{\mathrm{a}}{ }^{\mathrm{b}}$, Kanako Ochi ${ }^{\mathrm{b}}$, Fumio Otsuka ${ }^{\mathrm{a}}$ \\ a Department of General Medicine, Okayama University Graduate School of Medicine, Dentistry and Pharmaceutical Sciences, Okayama, Japan \\ ${ }^{\mathrm{b}}$ Center for Education in Medicine and Health Sciences, Okayama University Graduate School of Medicine, Dentistry and Pharmaceutical Sciences, \\ Okayama, Japan \\ ${ }^{c}$ Department of Primary Care and Medical Education, Okayama University Graduate School of Medicine, Dentistry and Pharmaceutical Sciences, Okayama, \\ Japan
}

\section{A R T I C L E I N F O}

\section{Article history:}

Received 9 May 2020

Received in revised form

12 June 2020

Accepted 24 June 2020

Available online 16 July 2020

\section{Keywords:}

Antimicrobial resistance

Antibiotic literacy

Antibiotics

Students

Medical education

\begin{abstract}
A B S T R A C T
Antimicrobial resistance (AMR) is an urgent global issue. After the AMR action plan was introduced in 2016, a study on antibiotic literacy (i.e., awareness, knowledge, and attitude relating to antimicrobial use) among clinicians and lay people was conducted in Japan. However, no studies have hitherto targeted medical students who are expected to have a high level of antibiotic literacy. The present study was conducted between September 2019 and February 2020, enrolling undergraduate students at Okayama University Medical School. We collected data using a paper-based questionnaire form with 11 questions about antibiotic literacy. The response rate was 93.8\% (661/705 students). Overall, $92.6 \%$ of the students knew that antibiotics inhibit the growth of bacteria. Student reporting that antibiotics could treat the common cold accounted for 77.0\% (Year 1), 50.9\% (Year 2), 48.2\% (Year 3), 49.1\% (Year 4), 23.8\% (Year 5), and $26.2 \%$ (Year 6). Only 43 (6.5\%) had heard about the AMR action plan. The study data suggested that medical students' level of literacy on antimicrobial use should be further enhanced to address AMR and promote antimicrobial stewardship.
\end{abstract}

(c) 2020 Japanese Society of Chemotherapy and The Japanese Association for Infectious Diseases. Published by Elsevier Ltd. All rights reserved.
Antimicrobial resistance (AMR) has become an emerging public health concern worldwide. Following the Global Action Plan on Antimicrobial Resistance [1], an AMR action plan was launched in Japan in 2016 [2], aiming to reduce the overall use of antimicrobials by $33 \%$ over the $2013-2020$ period. To this end, wise antimicrobial use should be highly recommended in every medical situation. Although education plays an essential part in antimicrobial stewardship [3], the contents of proper antimicrobial use has not been well incorporated into the curricula of medical universities. We hypothesize that Japanese medical students might have been

\footnotetext{
Abbreviations: AMR, antimicrobial resistance.

I ICMJE Statement: H. Hagiya was responsible for the organization and coordination of the study, and was the chief investigator and responsible for the data analysis. H. Ino, K. Tokumasu, H. Ogawa, T. Miyoshi, K. Ochi, and F. Otsuka helped developing the study design. All authors contributed to the writing of the final manuscript.

* Corresponding author. Department of General Medicine, Okayama University Graduate School of Medicine, Dentistry and Pharmaceutical Sciences, 2-5-1 Shikata-cho, Kita-ku, Okayama 700-8558, Japan.

E-mail address: hagiya@okayama-u.ac.jp (H. Hagiya).
}

provided fewer opportunities of learning about antimicrobial use than those required in clinical settings. Therefore, most of them graduate from the medical schools without the "antibiotic literacy."

To date, several surveys on the antimicrobial awareness have been conducted in Japan, focusing on pediatricians [4,5] and physicians [6,7], but not targeting medical students. In this study, we aimed to investigate the current status of antibiotic literacy among Japanese medical students.

We carried out this study with undergraduate students of Okayama University Medical School between September 2019 and February 2020. Medical students in our university take lectures on bacteriology, virology, and infectious diseases during 3rd grade year. We used a paper-based self-administered questionnaire consisting of 11 questions related to antibiotic literacy. Rates were calculated on the basis of the numbers of responses as denominators. The study protocol was accepted by Institutional Review Board of Okayama University Hospital (No. 1906-039). Informed consent was obtained from all of the students.

The response rate was $93.8 \%$ (661/705 medical students). Table 1 shows that almost all students $(659,99.7 \%)$ reported knowing the term "antibiotics". Regarding the benefits of antibiotics, $92.6 \%$ of 
Table 1

Frequencies and rates of students, by answer option and year of medical education.

\begin{tabular}{|c|c|c|c|c|c|c|c|}
\hline & Year 1 & Year 2 & Year 3 & Year 4 & Year 5 & Year 6 & Total \\
\hline Number of students & 114 & 117 & 122 & 126 & 109 & 117 & 705 \\
\hline Number (rate) of responses & $113(99.1)$ & $114(97.4)$ & $110(90.2)$ & $116(92.1)$ & $105(96.3)$ & $103(88.0)$ & $661(93.8)$ \\
\hline Do you know the term "antibiotics?" [YES] & $113(100)$ & $114(100)$ & $109(99.1)$ & $116(100)$ & $104(99.0)$ & $103(100)$ & 659 (99.7) \\
\hline \multicolumn{8}{|l|}{ What are the benefits of antibiotics? ${ }^{\mathrm{a}}$, } \\
\hline 1) antipyretic 2) pain relief 3) antitussive 4) inhibit bacterial growth & $102(91.1)$ & $102(93.6)$ & $105(96.3)$ & $108(95.6)$ & $102(97.1)$ & $93(94.9)$ & $612(92.6)$ \\
\hline $\begin{array}{l}\text { When visiting a doctor for the common cold, do you expect him or } \\
\text { her to prescribe antibiotics? [YES] }\end{array}$ & $25(22.3)$ & $20(17.5)$ & $18(16.8)$ & $25(21.6)$ & $12(11.7)$ & $16(15.5)$ & $116(17.5)$ \\
\hline Have you ever thought of using unprescribed antibiotics? [YES] & $33(29.7)$ & $33(28.9)$ & $42(38.5)$ & $55(47.4)$ & $40(38.1)$ & $49(47.6)$ & $252(38.1)$ \\
\hline Do you take up all the antibiotics prescribed at clinics? [YES] & $56(50.5)$ & $67(59.3)$ & $67(61.5)$ & $69(61.1)$ & $73(70.2)$ & $55(53.4)$ & $387(58.5)$ \\
\hline \multicolumn{8}{|l|}{ How do you deal with left-over antibiotics? ${ }^{a}$} \\
\hline 1) Keeping them for use when needed & $36(35.6)$ & $34(34.9)$ & $36(37.9)$ & $42(41.2)$ & $23(25.8)$ & $38(40.4)$ & $209(31.6)$ \\
\hline 2) Taking them when falling ill & $16(15.8)$ & $19(19.0)$ & $20(21.1)$ & $23(22.5)$ & $21(23.6)$ & $21(22.3)$ & $120(20.3)$ \\
\hline 3) Giving them to others & 0 & 0 & 0 & 0 & 0 & 1 & $1(0.2)$ \\
\hline 4) Throwing them away & $42(37.8)$ & $42(42.0)$ & $35(36.8)$ & $31(30.4)$ & $37(41.6)$ & $30(31.9)$ & $217(36.7)$ \\
\hline $\begin{array}{l}\text { Have you ever taken antibiotics given by your family members or } \\
\text { acquaintances? [YES] }\end{array}$ & $38(33.9)$ & $41(36.0)$ & $39(35.5)$ & $41(35.3)$ & $40(38.1)$ & $36(35.0)$ & $235(35.6)$ \\
\hline Do you know about the "AMR action plan?" [YES] & $1(0.9)$ & $5(4.4)$ & $14(12.8)$ & $6(5.2)$ & $4(3.8)$ & $13(12.7)$ & $43(6.5)$ \\
\hline
\end{tabular}

Rates (\%) are denoted in the parentheses.

a Multiple-choice question.

b For this question, only the numbers of students who selected option 4 are presented in this table.

the students were aware that antibiotics help inhibiting bacterial growth. Additionally, $30.0 \%$ of all medical students answered that antibiotics were effective in treating diseases caused by viruses (64.6\%, 45.6\%, 27.3\%, 19.8\%,11.4\%, and 7.8\% of students from Year 1 to Year 6, respectively). In particular, $46.4 \%$ of all students misunderstood that antibiotics could be used as an option of treatment for the common cold $(77.0 \%, 50.9 \%, 48.2 \%, 49.1 \%, 23.8 \%$, and $26.2 \%$ of students from Year 1 to Year 6). Students who thought that influenza could be treated with antibiotics accounted for $26.5 \%$ (60.2\%, $32.5 \%, 25.5 \%, 17.2 \%, 11.4 \%$, and $9.7 \%$ of students from Year 1 to Year 6) (Fig. 1).

Approximately $20 \%$ of the medical students expected physicians to prescribe antibiotics to them to treat the common cold. Nearly $40 \%$ of them responded that they had thought of taking unprescribed antibiotics. Around $60 \%$ of all students reported taking up all the antibiotics they were prescribed. Regarding how to deal with the left-over antibiotics, $31.6 \%$ of the students said they kept those medications because they might need them later, while $36.7 \%$ chose to throw them away. One-fifth of the students used antibiotics when falling ill, and nearly one-third used these medications given to them by their family members or acquaintances. Nearly no one gave the remaining antibiotics to other people. Fortythree students (6.5\%) had heard about the "AMR action plan", which was launched and promoted by the Japanese government in 2016 (Table 1).

Although this study was conducted in only one setting (Okayama University), it may be the first attempt to uncover Japanese medical students' antibiotic literacy. Antibiotics are the drugs possibly most

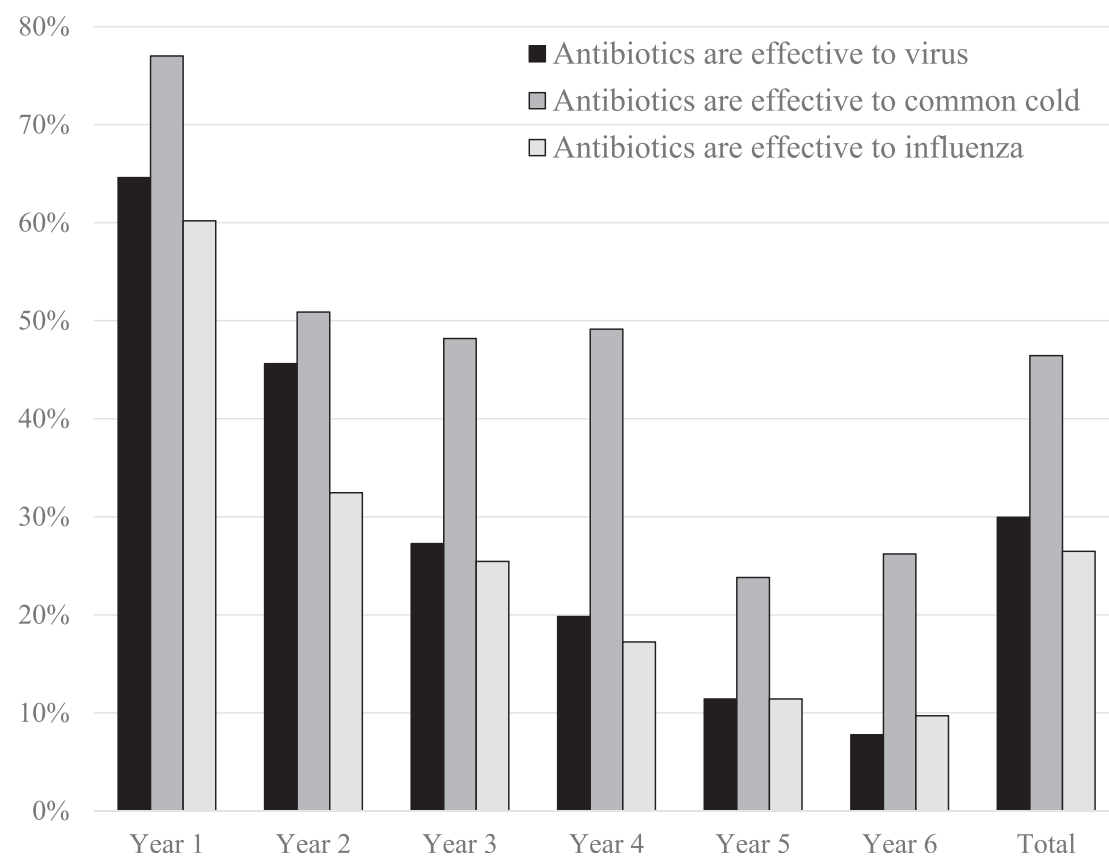

Fig. 1. Rates of medical students misunderstanding that antibiotics could treat viral diseases, by year of medical education. 
commonly prescribed by young doctors without sufficient instructions from senior doctors or specialists. The attitude of professionalism is mostly developed in the very beginning of training, and thus, professional education in antimicrobial prescribing should involve not only postgraduates but undergraduates [8]. In fact, the Japanese Ministry of Education, Culture, Sports, Science and Technology stresses an importance of appropriate use of antimicrobials in the Medical Education Model Core Curriculum [9]. According to a cross-sectional, web-based survey with European final-year medical students, more than half of the respondents expressed the need for more opportunities of education in antibiotic use [10]. The Global Action Plan underlined the values of education and training [1], and the faculty members should further provide such a learning opportunity with a clear attainment target.

Our study findings show that more than $90 \%$ of medical students knew that antimicrobials can inhibit bacterial growth. However, relatively high rates of students answered that the antibiotics could be used to treat viral diseases, such as the common cold and influenza. Notably, almost half of all students and a quarter of finalyear students were found to have a false understanding that the antibiotics helped treat the common cold. In Japan, the overuse of antibiotics for acute respiratory infections remains in every clinical situation [11,12], indicating the importance of undergraduate education in antibiotic literacy. The AMR action plan was little known by medical students (6.5\%), though it has been carried out for more than 3 years [2]. A previous study showed that $44 \%$ of physicians had never heard of this plan [7]. These findings also suggest that university educators should further familiarize them with the national policy on AMR countermeasures.

There have existed several approaches to enhancing medical students' antibiotic literacy, one of which is providing more learning opportunities for students and integrating more contents related to antibiotic use into the university curriculum. A recent survey showed that medical schools in the United Kingdom allocated a median of 17.8 class hours to antimicrobial stewardshiprelated contents [13]. Despite the unavailability of related data in the entire Japan, those of this study suggest that Japanese medical students lack opportunities to learn about antimicrobial use. Additionally, teaching methods should be devised to them effectively. A prospective controlled intervention study demonstrated that e-learning and internet-based learning contribute to improving medical students' long-term antimicrobial prescribing behavior [14]. Even though students' antibiotic literacy is improved, it is worth noting that the gaps between knowledge and antibiotic prescribing still exist in clinical settings [15]. Therefore, a continuous education scheme for under- and post-graduates is absolutely imperative. The poor understanding among 1 st grade students may reflect common knowledge and basical attitude of high-school graduates. In this era of AMR, a basic education that enhances the antibiotic literacy in teenagers is warranted as well.

The strength of our study lies in the high response rate of respondents, ranging from $88.0 \%$ to $99.1 \%$. However, the study has several limitations that need to be addressed. First, the study was conducted on medical students at only one university. Second, the cross-sectional nature of the study would lead to information bias. Finally, we used a self-administered questionnaire to collect data, and therefore, undergraduate students' self-reports might affect the accuracy of the collected data.
In summary, medical students at Okayama University Medical School appeared to have inadequate antibiotic literacy, and therefore, they should be provided with additional education in antimicrobial stewardship during the undergraduate period. We suggest that a further comprehensive survey with a larger sample size is required to assess medical students' awareness, preparedness, and attitude toward antimicrobial stewardship.

\section{Funding sources}

None to report.

\section{Declaration of Competing Interest}

None to report.

\section{References}

[1] WHO. Global action plan on antimicrobial resistance. Available from: http:// apps.who.int/gb/ebwha/pdf_files/WHA68/A68_R7-en.pdf?ua\%221; 2015.

[2] The Government of Japan. National action plan on antimicrobial resistance (AMR). Available from: https://www.mhlw.go.jp/file/06-Seisakujouhou-10900000Kenkoukyoku/0000138942.pdf; 2016-2020 (Accessed 23rd March 2020).

[3] Dellit TH, Owens RC, McGowan JE, Gerding DN, Weinstein RA, Burke JP, et al. Infectious diseases society of America and the society for healthcare epidemiology of America guidelines for developing an institutional program to enhance antimicrobial stewardship. Clin Infect Dis 2007;44:159-77.

[4] Ohishi T, Toriyabe S, Uchiyama M. Study of the proper use for antimicrobial to children with respiratory infectious diseases-Analysis of the questionnaire survey to the pediatricians- (in Japanese). J Pediatr Infect Dis Immunol 2009;21:117-23.

[5] Kurosaki T, Ishiwada N, Sato Y. Results of a questionnaire for antimicrobial stewardship in Chiba pediatric association (in Japanese). Kansenshogaku Zasshi 2018;92:86-7.

[6] Nakahama C, Muratani T. The problem of bacterial antimicrobial resistance in outpatients and the appropriate use of oral antimicrobial agents (in Japanese). Jpn J Chemother 2018;66:185-202.

[7] Gu Y, Fujitomo Y, Soeda H, Nakahama C, Hasegawa N, Maesaki S, et al. A nationwide questionnaire survey of clinic doctors on antimicrobial stewardship in Japan. J Infect Chemother 2020;26:149-56.

[8] Pulcini C, Gyssens IC. How to educate prescribers in antimicrobial stewardship practices. Virulence 2013:4:192-202.

[9] Medical Education Model Core Curriculum Coordination Committee \& Medical Education Model Core Curriculum Expert Research Committee. Model Core curriculum for medical education in Japan [Internet]. Available from: https:// www.mext.go.jp/component/a_menu/education/detail/_icsFiles/afieldfile/ 2018/06/18/1325989_30.pdf; 2018 (Accessed 9th June 2020).

[10] Dyar OJ, Nathwani D, Monnet DL, Gyssens IC, Lundborg CS, Pulcini C. Do medical students feel prepared to prescribe antibiotics responsibly? Results from a cross-sectional survey in 29 European countries. J Antimicrob Chemother 2018;73:2236-42.

[11] Teratani Y, Hagiya H, Koyama T, Adachi M, Ohshima A, Zamami Y, et al. Pattern of antibiotic prescriptions for outpatients with acute respiratory tract infections in Japan, 2013-15: a retrospective observational study. Fam Pract 2019;36:402-9.

[12] Koyama T, Hagiya H, Teratani Y, Tatebe Y, Ohshima A, Adachi M, et al. Antibiotic prescriptions for Japanese outpatients with acute respiratory tract infections (2013-2015): a retrospective Observational Study. J Infect Chemother 2020;26:660-6.

[13] Castro-Sánchez E, Drumright LN, Gharbi M, Farrell S, Holmes AH. Mapping antimicrobial stewardship in undergraduate medical, dental, pharmacy, nursing and veterinary education in the United Kingdom. PloS One 2016;11: e0150056.

[14] Sikkens JJ, Caris MG, Schutte T, Kramer MHH, Tichelaar J, Van Agtmael MA. Improving antibiotic prescribing skills in medical students: the effect of elearning after 6 months. J Antimicrob Chemother 2018;73:2243-6.

[15] Abbo LM, Cosgrove SE, Pottinger PS, Pereyra M, Sinkowitz-Cochran R, Srinivasan A, et al. Medical students' perceptions and knowledge about antimicrobial stewardship: how are we educating our future prescribers? Clin Infect Dis 2013;57:631-8. 